\title{
Modeling and Design of a New Type of Self-Balancing Obstacle Vehicle
}

\author{
LV Qing-ying \\ College of Mechanical and Electric Engineering, \\ Changchun University of Science and Technology, \\ Changchun 130022, China \\ E-mail: 1176865640@qq.com
}

\begin{abstract}
In this paper, the design development of a new type of self-balance obstacle car, it can climb over obstacles, across the gully. The car is on left and right wheels independently driven, through advanced microprocessor. The inclination sensor in control system and the mechanical body device to control about two swing arm swinging back and forth, achieve vehicle self-balance and obstacle function. Walking performance analysis shows that the vehicle has good maneuverability and trafficability and the mathematical model of the vehicle has been carried out, which verifies the rationality of the design.
\end{abstract}

Keywords: self-balancing; obstacle; mechanical structure; modeling; walking;

\section{INTRODUCTION}

The two wheeled vehicle is a new transport vehicle, following motorcycle car. Its technology has been used in many fields, such as mechanical, control, sensor, artificial intelligence and so on. It has good interactivity, applicability and autonomy. Currently, there are many research results about the self-balanced car at home and abroad, such as Segway ${ }^{[1]}$ invented by American inventor Kamen Dean and his research team. Switzerland Federal Institute of industrial research and development of the two wheeled mobile robot Joe ${ }^{[2]}$, etc. Taiwan neutral University, China University of science and technology ${ }^{[3-4]}$ and also advanced research results. First of all, it covers an area of small, little and flexible, can travel on the road. Secondly, it can effectively reduce the fuel consumption clean the atmosphere to reduce environmental pollution. The design focus on the mainstream of future traffic means of transport, but also of climbing obstacle capability of low, it is difficult in the unstructured ground walking. In view of this paper designs and develops a new rounds of self-balanced fast moving obstacle crossing mechanism can be flat walk, climb over obstacles, across the ravines, has good mobility and through.

\section{FUNCTION ANALYSIS AND SCHEME DESIGN}

The car in the unstructured road must have a certain function obstacle. In addition, it should also have a certain sense of perception and intelligence, Its functional planning is shown in figure 1.

\author{
YANG Liu \\ College of Mechanical and Electric Engineering, \\ Changchun University of Science and Technology, \\ Changchun 130022, China. Corresponding \\ E-mail: yangliu_1114@163.com
}

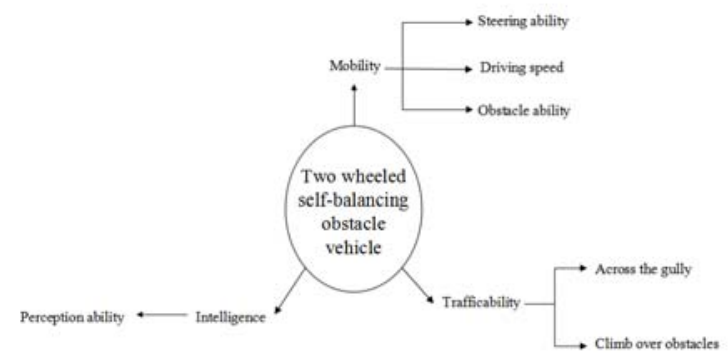

Figure 1 The function planning of two wheeled self- balancing vehicle obstacle

As a self-balancing over obstacle mechanism of this kind of robot, the obstacle moves typical: crawler, foot type wheel. Table 1 shows the advantages and disadvantages of several classical methods of mobile obstacle $^{[5-11]}$.

TABLE 1 TYPICAL METHODS AND COMPARES THE ADVANTAGES AND DISADVANTAGES OF MOBILE OBSTACLE

\begin{tabular}{ccc}
\hline $\begin{array}{l}\text { Mobile } \\
\text { mode }\end{array}$ & Advantage & Shortcomings \\
\hline $\begin{array}{c}\text { Track } \\
\text { type }\end{array}$ & $\begin{array}{c}\text { Support area is large, } \\
\text { and the adaptability } \\
\text { is strong. } \\
\text { The pedestrian }\end{array}$ & $\begin{array}{c}\text { Ground damage, flexibility } \\
\text { difference }\end{array}$ \\
foot & $\begin{array}{c}\text { Slow moving speed, } \\
\text { requirement, high } \\
\text { climbing ability }\end{array}$ & $\begin{array}{c}\text { Control implementation } \\
\text { complexity, }\end{array}$ \\
& $\begin{array}{c}\text { Low stability and reliability } \\
\text { Wheel }\end{array}$ & Simple operation, \\
type & fast & Relative obstacle capability \\
& & Poor
\end{tabular}

Because of this topic is the design of self -balancing obstacle car in climbing requirements analysis based on, light weight, smooth operation, simple operation, flexible, green environmental protection, the wheeled mobile robot with low cost, simple structure and control, high energy utilization rate. Therefore, a new type of movement is adopted, which is the structure of wheel leg.

\section{THE WORKING PRINCIPLE OF TWO WHEELED SELF-BALANCING OBSTACLE CAR}

Since the two wheeled self-balancing electric vehicle structure, which makes its center of gravity in the upper and lower, it is not in control of the state (or static) for an unstable system. However, you can use the inverted pendulum control principle of the system, by 
microprocessor control enables it to such as inverted pendulum as stable in a balanced position, and in maintaining the equilibrium state in accordance with the instructions of the user requirements of normal operation. Two wheeled self-balancing electric vehicle is actually a combination of a linear inverted pendulum and a rotary inverted pendulum, which is consistent with the inverted pendulum system. More vividly, the work principle of self-balancing electric vehicles is more like the process of human walking.

Two basic idea of self-balance obstacle car is: when the measure inclination angle sensor to detect to the body is tilted, the control system generates a corresponding torque according to the measured angle, by controlling the motor drive two wheels towards the body to fall in the direction of movement, the wheel quickly two direction in order to maintain the dynamic balance of the car itself. At the same time, encounter obstacles, swinging arm is driven by a motor car can move certain height over obstacles, at this time, self-balancing system and obstacle navigation system work at the same time ${ }^{[12]}$.

\section{MECHANICAL STRUCTURE DESIGN AND WALKING PERFORMANCE ANALYSIS}

\section{A. Mechanical structure design}

Application of CATIA software to establish a three-dimensional model of self-balancing vehicle obstacle, as shown in figure 1.The overall structure of self-balancing car obstacle including wheel, swing arm, vehicle control system, etc.

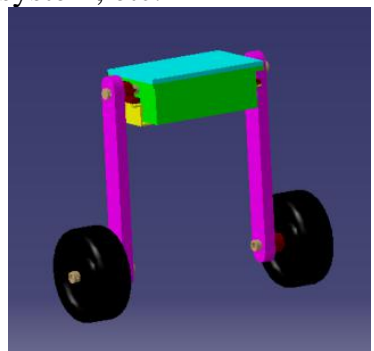

Figure 2 The CATIA model of self-balancing obstacle car

\section{$B$ Walking performance analysis}

When walking on flat ground, the arms are placed on both sides of the trolley to the ground, as shown in Figure 2a.When the body cannot keep the balance between the front and rear, with the help of the angle sensor, so that the two swing arm is driven by the motor independently, as shown in figure 2bc.The overall control system to keep the dynamic state of the unstable state to keep the car stable. The overall control system is to keep the dynamic state of the unstable state to keep the car stable.

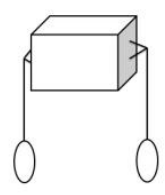

(a)

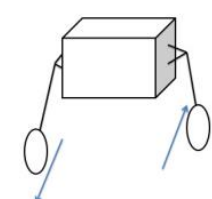

(b)

(c)

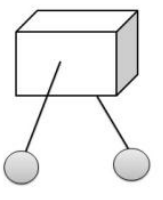

Figure 3 Motion planning of the vehicle when the motor is flat When walking encounter raised obstacles, the vehicle's attitude as shown in figure 3.With the aid of a sensor, a control arm is controlled to form an angle in the vertical direction, and a high degree of cross barrier is raised.
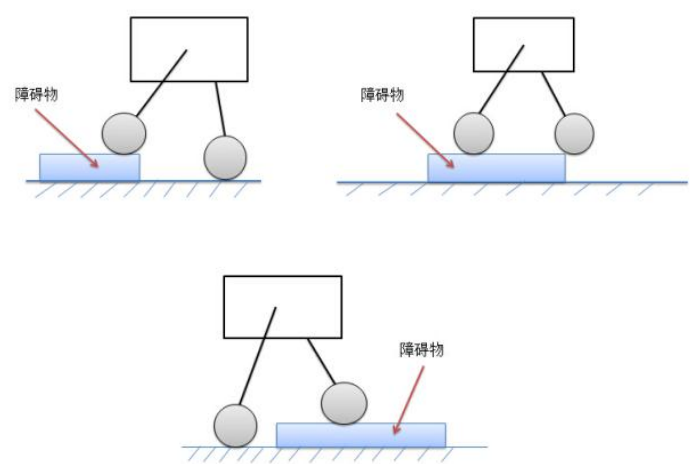

Figure 4 The vehicle obstacle attitude

\section{MATHEMATICAL MODELING}

Two wheeled self-balancing vehicle obstacle is mainly composed of wheels, swing arm, and the vehicle control system is composed of four parts, which the motor driven wheel is the active mechanism, and the arm, the body itself is the servo mechanism, to achieve the system balance, it is to control the motor to achieve a positive reversal movement to achieve torque. Assume that the body is out of balance tilted forward, than we have to have motors drives the wheels to have an acceleration to keep the body in balance, so the system can maintain the equilibrium state. Due to the complexity of the system, the non-stability and the nonlinearity of the system, the problems such as the following problems, such as the following problems, such as the following, the tracking and the robustness of the system ${ }^{[13-14]}$.

Using Newton method for mechanical analysis, the main parameters that affect the balance car: the weight of the body, the radius of the wheel, the center of gravity .In order to maintain the dynamic balance of the system, the center of gravity of the body should be in a certain angle range of the center line of the vehicle. The system is assumed to be rigid, and the lateral slip between the ground and the tire is neglected, the pendulum angle of the two swing arms $\theta_{1}=\theta_{2}=\theta$.According to the model of the car body model, the mechanical model is established by the force analysis of the 1 body model. Because there is no displacement of the $\mathrm{Y}$ axis, the mechanical model of the $\mathrm{X}$ axis is established.

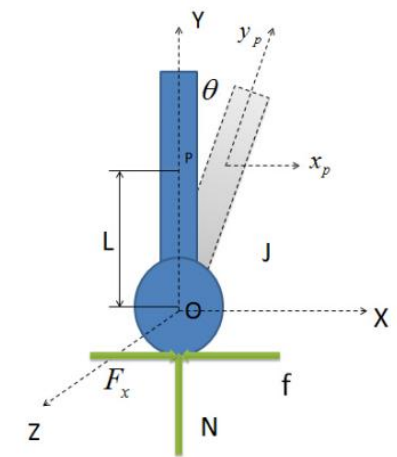

Figure 5 Body structure diagram 
Left wheel mechanical modeling:

$$
\begin{aligned}
& m \ddot{x}_{l}=f_{l}-F_{l x} \\
& \frac{J_{w}}{R} \ddot{x}_{l}=T_{l}-f_{l} R
\end{aligned}
$$

Right wheel mechanics model:

$$
\begin{aligned}
& m \ddot{x}_{r}=f_{r}-F_{r x} \\
& \frac{J_{w}}{R} \ddot{x}_{r}=T_{r}-f_{r} R
\end{aligned}
$$

Among them, and for the left and right wheel horizontal coordinates [m]., respectively in the face about the role of the wheel friction [N], respectively for wheel in the horizontal direction force $[\mathrm{N}]$., respectively for the motor to the wheel torque $[\mathrm{kg} \mathrm{m}]$, said wheel around $\mathrm{Z}$ axis direction of moment of inertia [kgm2], said wheel radius [m],said wheel weight $[\mathrm{kg}]$.

Car body mechanics modeling:

$$
\begin{gathered}
M \ddot{x}_{p}=F_{l x}+F_{r x} \\
J_{p} \ddot{\theta}=\left(N_{l}+N_{r}\right) L \sin \theta-\left(F_{l x}+F_{l x}\right) L \cos \theta-\left(T_{l}-T_{r}\right) \\
M \ddot{y}=N_{l}+N_{r}-M g \\
J_{\delta} \ddot{\delta}=\frac{D}{2}\left(F_{l x}-F_{r x}\right)
\end{gathered}
$$

Car body center of gravity:

$$
\begin{aligned}
& x_{p}=x+L \sin \theta \\
& y_{p}=L \cos \theta
\end{aligned}
$$

Where respectively for the coordinates of the centre of gravity of the body and the $\mathrm{X}$ and $\mathrm{Y}$ axes, respectively for the face of wheel force [N] . L for the body center of gravity to the origin of the coordinate distance [m] . Bodywork around the origin of inertia [kgm2], bodywork around the $\mathrm{X}$ axis of inertia [kgm2], $\mathrm{D}$ is distance between two wheels. Here, the left and the right two extended $\mathrm{x}$ axis angle respectively, $M$ for the weight of the vehicle body [kg].

\section{CONCLUSION}

In based on the analysis of the car function design scheme, design model can cross the barrier of two wheeled self-balance obstacle car. Secondly, the working principle and the motion planning of the car are described, and the movement attitude and the way of walking are explained in two cases. Established a mechanical model of the self-balancing obstacle vehicle. The robot can not only on the flat ground fast moving, but also take into account the legged mobile robot of good obstacle, make it better through a rough road.

\section{ACKNOWLEDGMENT}

LV Qiong-ying (1963-), male, Changchun, associate professor, doctor, doctoral supervisor, mainly engaged in optical, mechanical and electronic integration system, is project manager of the National 863 major projects.

\section{REFERENCE}

[1] http://www. Segway.com/.

[2]Felix Grasser, Aldo D’Arrigo, Silvio Colombi, Alfred C. Rufer. JOE: A Mobile, Inverted Pendulum. IEEE Transactions on Industrial Electronics . 2002, 49(1):107 114.

[3] ZHOU Xuanda. Design and implementation of the two wheeled vehicle[D].Taiwan: National Central University, 2007.

[4] XU Guohu, TAN Min. Development status and trend of mobile robot [J].Robot technology and Application, 2001, 14 (3) : 7-14.

[5] TU Yunwu. Research on self-balancing control system[D].Hefei: University of Science and Technology of China, 2004.

[6] ZHENG Hui, WANG Min, etc. Design and kinematics analysis of the hybrid robot with wheel leg[J]. Mechanical transmission2015, 01:57-61.

[7] CHEN Diansheng, HUANG Yu,etc. Obstacle analysis and Simulation of wheel legged robot [J]. Journal of Beihang University, 2009, 03:371-375.

[8] MA Zerun. Research on the mechanism design of the robot's mechanism design of the wheel leg type of alien robot[D].Shanghai Jiao Tong University,2014.

[9] CHEN Changzheng, XIANG Hongwei,etc. Dynamic analysis of a deformable tracked robot over a step [J].Journal of Shenyang University of Technology, 2015,02:165-170.

[10] CHEN Shuyan,CHEN Wenjia.Survey on the research of crawler type mobile robot[J]. Mechanical and electrical engineering, 2007,12:109-112.

[11] MEI Hong,LI Yunxia,etc. A mobile robot with climbing obstacle capability [J].Machine tools and hydraulic, 2013,22:14-16.

[12] TU Yunwu, XU Junyan, etc.Modeling and Simulation of self-balancing control system[J].Journal of system simulation,2004,04:839-841.

[13] Liangliang Cui, Yongsheng Ou, Junbo Xin,Dawei Dai,Xiang Gao. Control of a Two-Wheeled Self-Balancing Robot with Support Vector Regression Method[A].IEEE Beijing Section. Proceedings of 2014 4th IEEE International Conference on Information Science and Technology[C].IEEE Beijing Section:,2014:5.

[14] WANG Liangcheng, YANG Zhimin, etc. Design and implementation of two wheeled self-balancing vehicle [J].Laboratory Science, 2012,06:52-55.

[15] CHENG Gang, QU Chengli, etc. Study on controllable angle of two wheeled self-balancing vehicle [J]. Servo control, 2008,06:51-53. 